\title{
STUDIES ON THE MECHANISM OF BACTERIAL BIOLUMINESCENCE. EVIDENCE COMPATIBLE WITH A ONE ELECTRON TRANSFER PROCESS AND A CIEEL MECHANISM IN THE LUCIFERASE REACTION
}

\section{Peter MACHEROUX, Jens ECKSTEIN and Sandro GHISLA}

Faculty of Biology, University of Konstanz, D-7750 Konstanz, FRG

Introduction and Premises

In the key step of bacterial bioluminescence a long chain aldehyde is oxidized to the corresponding fatty acid, with the concomitant generation of an excited state. This oxidation is carried out by a flavin-C(4a)-hydroperoxide, possibly over a flavin-C(4a)-peroxyhemiacetal [1,2]. The mechanism of the key step, the generation of the excited emitter, is still unclear. None of the several previous proposals, including a "Baeyer-villiger" oxidation, or a dissociative electron transfer mediated by a cysteine sulfhydril, were satisfactory $[3,4]$. As introduced in the preceding review article [5], the recently proposed CIEEL mechanism (Chemically Initiated Electron Exchange Luminescence) [6] merits careful consideration. In preliminary experiments [7,8] aiming at its verification, we attempted a correlation of the rate of emission decay with the redox potential of flavins, substituted at various ring positions. The rather poor correlation obtained was, however, attributed to specific effects induced by the flavin modification, e.g. alteration of protein-flavin interactions. It has been shown, using FMN analogues carrying various substituents at position $\mathrm{C}(8)$, that these are recognized by luciferase, and are competent in bioluminescence, suggesting that this position is "free", 
i.e. exposed to solvents $[9,10]$. Based on this we reasoned, that modifications restricted to this position would conserve intact flavin-protein interactions, and not prejudice the catalytic event.

An important assumption needs discussion: Verification of the CIEEL mechanism according to schuster [6] bases on a correlation with the redox potential of the donor involved, in our case this would be $N(5)$ of $4 \mathrm{a}, 5$-dihydroflavin [5]. Concrete values on the redox potential of a couple Flox = $4 a, 5$-dihydro-Flrea do not exist. 4a,5-dihydro-flavins are, however, simply tautomeric forms of 1,5-dihydro-flavins,<smiles>Cc1cc2c(cc1C)N(C)C1=NC(=O)NC(=O)C1N2</smiles>

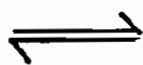<smiles>Cc1cc2c(cc1C)N(C)c1[nH]c(=O)[nH]c(=O)c1N2</smiles>

the second beeing clearly thermodynamically favored. It is reasonable to assume, that the free energy difference between the two forms is not very large: Alkyl substituents have been found to migrate reversibly between the two positions $[11,12]$. Slight variations of the alkylation conditions lead to $\mathrm{N}(5)$ or $\mathrm{C}(4 \mathrm{a})$ derivatives of $\mathrm{Fl}_{\text {rea }} \mathrm{H}^{-}$. Adduct formation of some flavins with sulfite has been found to yield an equilibrium mixture of 5- and 4a-adducts [13]. The difference in free energy between the 4a,5- and the 1,5tautomer thus probably is much smaller than that between Flox and $F l_{\text {red. }}$. Consequently substituents affecting the Flox/1,5-Hz-Fly redox potential should affect that of $\mathrm{Flox} / 4 \mathrm{a}, 5-\mathrm{H}_{2}-\mathrm{Fl}$ red in an analogous way. As a further test, we resorted to the classical Hammett correlation, since the key "CIEEL - step" can be viewed formally as an (internal) 
activation of a hydroperoxihemiacetal by a p-X-substituted o-phenylene (di)amine, in which "only" $\mathrm{x}$ is varied:

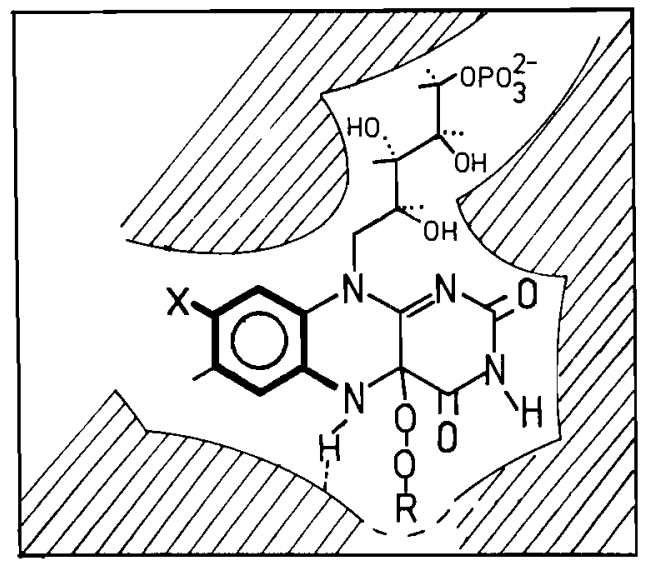

By introducing a reference system (i.e. nonsubstituted FMN) the Hammett equation can be formulated as follows:

$$
\log \mathrm{k} / \mathrm{k}_{\mathrm{o}}=\mathrm{r} * \sigma^{\prime} \text {, }
$$

where $k_{0}$ is the rate constant of the reference system, $r$ (rho) is the "reaction parameter" and $\sigma^{\prime}$ is the "substituent parameter". We have estimated $\sigma^{\prime}$ and $r$ for a series of 8 substituted flavins, and used the values for the plot of Fig. 2 described below.

\section{Results and D1scussion}

We have expanded the previous measurements [7] using the 8 flavins shown in the figures of redox potential in the range -50 to $-320 \mathrm{mV}$. The correlation of $\log \mathrm{k}$ (rate constant of the light emission decay) with the redox potential plotted according to schuster [6] yields a slope of $-14 \mathrm{~V}^{-1}$. This means a value of 0.8 for the so called "diagnostic constaıt" or "Brönsted slope" $\alpha$, which has been suggested to 
reflect the extent of one-electron-transfer occuring during a reaction $[6,14,17]$. $\alpha$ can have values between 0 and 1 , the second extreme reflecting complete charge separation. According to Schuster values of $\alpha<1$, can also be compatible with transfer of one electron, when changes in bonding geometry are taken into account.

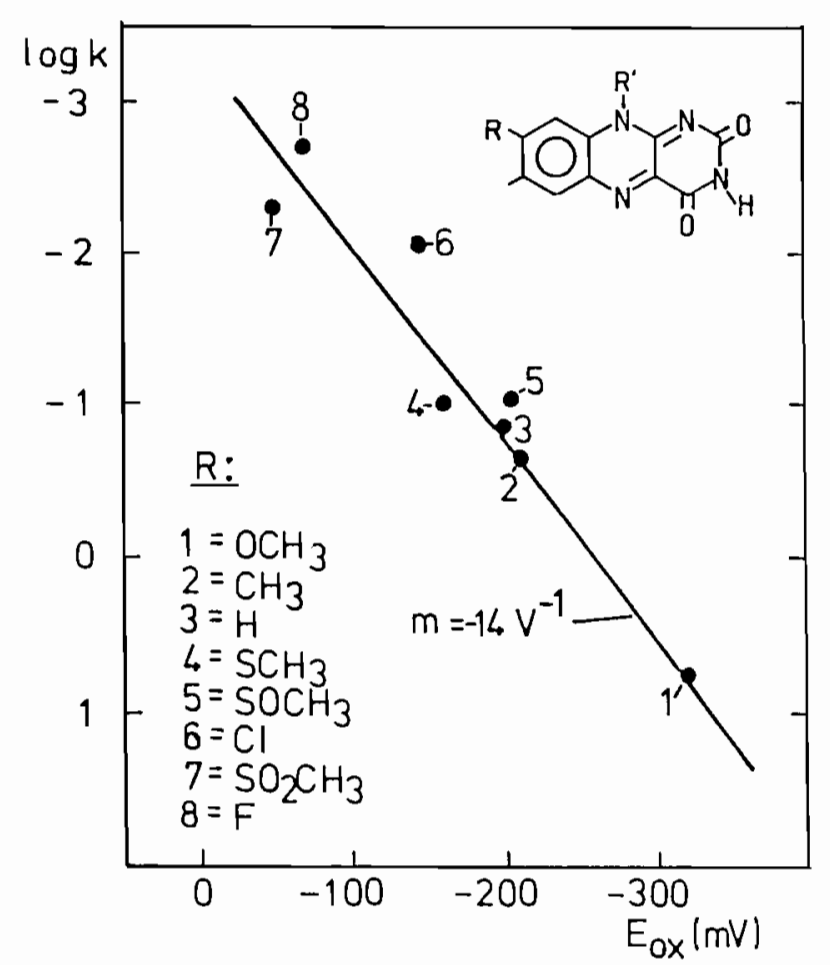

Fig. 1)

Dependence of luminescent decay rate on the redox potential of 8-substituted FMN derivates: The luminescence emission was measured in a dithionite assay [17]. The aldehyde was decanal at a final concentration of $\approx 4 \times 10^{-3} \mathrm{M}$. Luciferase and FMN were $6.7 \times 10^{-7} \mathrm{M}$ and $1 \times 10^{-8} \mathrm{M}$, respectively. The data shown are the average of at least 10 measurements. The FMN derivative \#3 is "180-FMN" (6,7-dimethyl-8-demthyl-FMN). The slope is $-14 \mathrm{~V}^{-1}$, it can also be expressed as $-\alpha / 2$.3RT, yielding a value of 0.8 for $\alpha$. 
The Hammett plot shown in Fig. 2 yields a reaction parameter of -0.8 . This value reflects a typical value for reactions, where radicals are involved $[15,16]$. It should be pointed out, that the $\sigma$ ' values were calculated by substituting the equilibrium constant $(K)$ in the classical Hammett equation with the redox potential according to the method of Kochi et.al.[17] using unsubstituted FMN as reference system.

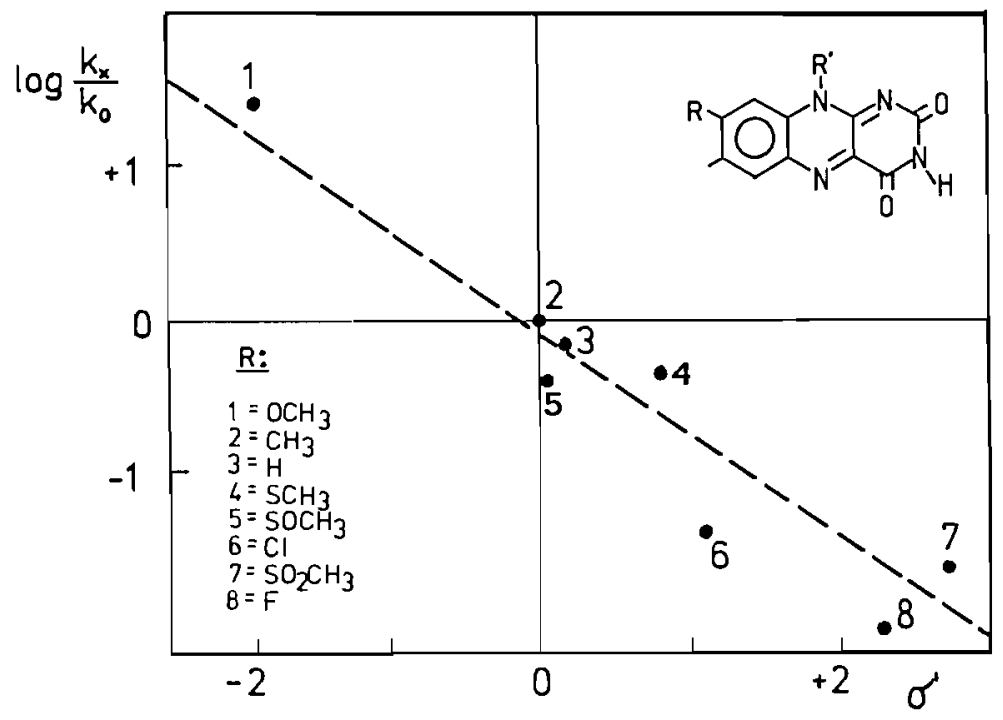

Fig. 2)

Correlation of $\log \mathrm{k} / \mathrm{k}$ o with the substituent parameters $\sigma^{*}$ in a Hammett-type plot: The FMN derivate \#3 is "1so-FMN" (6,7-dimethyl-8-demthyl-FMN). The slope corresponds to a value of -0.8 for the rate parameter $r$. 


\section{Conclugions}

Linear free energy relationships have been extensively studied for electron transfer and related reactions in both inorganic and organic systems, they allow reliable mechanistic conclusions [17]. Our value of $\alpha \approx 0.8$ clearly is compatible with Schuster's CIEEL mechanistic interpretation of luminescent reactions. In the examples reported by his group $\alpha$ had values $\approx 0.3$. According to Kochi et.al. [17] $\alpha$ Brönsted values of $0.5<\alpha<1$ can be interpreted with confidence to reflect the "intrinsic barrier" of a system for a one electron transfer process. The data were plotted according to Hammett also using classic $\sigma$ parameters. In this case the correlation is generally poorer and depends on the type of effect (M- or I-effect) the parameters were derived for. When the $M-$ and $I$-effected parameters are averaged $\left(\sigma^{+}\right)$a value $r \approx-1.7$ can be estimated. According to the data reviewed by Jaffe [15] values of $r>3$ or $r<-3$ are typical for processes involving ionic transition states. Wells [16] points out that radical mechanisms yield $r$ values $0 \pm 1$, and indeed a value $r=-0.76$ was found for the photohalogenation of substituted toluenes, a typical radical process. It should be pointed out that the coincidence of our value $r \approx-0.8$ with that of typical radical mechanism is remarkable. We would like to stress the point that this, of course, might be coincidental: since reliable data on chemical systems which might be taken as models for our reaction are not available, this cannot be taken as proof for a radical mechanism. On the other hand a Baeyer-villiger mechanism would predict the reaction rate to increase with increasing redox potential of the flavin. This mechanism should be reflected by a Hammett dependence with a positive slope. As a minimal interpretation our results are in disaccord with a Baeyer-villiger type mechanism. 


\section{References}

1. Hastings, J.W., C. Balny, C. Le Peuch P. and Douzou 1973. Proc.Natl.Acad.Sci.USA, 70, 3468-3489.

2. Ghisla, S., J.W. Hastings, W. Favaudon and J.M.Lhoste 1978. Proc.Natl.Acad.Sci.USA, 75, 5860-5863.

3. Hastings, J.W. and K.H. Nealson 1977. Annu.Rev. Microbiol., 31, 549-595.

4. Kosower, E.M. 1980. Biochem.Biophys.Res.Commun., 92, $356-364$.

5. Ghisla, S., J. Eckstein and P. Macheroux this volume.

6. a.) Koo, J.Y. and G.B. Schuster 1977. J.Am.Chem.Soc., $99 / 18,6107-6109$.

b.) Schuster G.B. 1979. Acc.Chem. Res., 12, 366-373.

7. Macheroux, P. 1986. Ph.D.Thesis Univers.Konstanz, FRG.

8. Macheroux, P., S. Ghisla, J.W. Hastings and M. Kurfürst 1984. In: Flavins and Flavoproteins (Bray R., P. Engel and S.G. Mayhew eds.), de Gruyter, Berlin, pp. 669-672.

9. Watanabe, T., K. Matsui, S. Kasai and T. Nakamura 1978. J.Biochem, 84, 1441-1446.

10.Chen, L. and T.O. Baldwin 1984. In: Flavins and Flavoproteins ( Bray R., P. Engel and S.G. Mayhew eds.), de Gruyter, Berlin, pp. 785-788.

11.Ghisla S., U. Hartmann, P. Hemmerich and F. Müller 1973. Liebigs Ann.Chem., 1388-1415.

12.Haas, W. and P. Hemmerich 1975. In: Reactivity of Flavins (Jagi, K. ed.), Univ. of Tokyo Press, pp. 1-13.

13. Bruice, T.C., L. Hevesi and S. Shinkai 1973. Biochem., 12, 2083-2089.

14.Wilson, T. 1985. In: Singlet $\mathrm{O}_{2}$ (Frimer, A. ed.), CRC Press Inc., II, pp. 37-65.

15.Jaffé, H.H. 1953. Chem.Rev., 53, 191-260.

16. Wells, P.R. 1963. Chem.Rev., 63, 171-219.

17.Fukuzumi, S. and J.K. Kochi 1983. Bull.Chem.Soc.Jpn., 56, 969-979.

18. Hastings, J.W., T.O. Baldwin and M.Z. Nicoli 1978 . Methods in Enzymology, 57, 135-152. 